Research Article

\title{
Prototype of an Expert System for the Selection of Aircraft Structural Materials
}

\author{
Xuelong Hao $\mathbb{D}^{1,2}$ Chen Wen, ${ }^{3}$ Ning Zhao, ${ }^{4}$ Lu Lu, ${ }^{1,2}$ Kai Zhang, ${ }^{5}$ and Donghui Zhang ${ }^{1,2}$ \\ ${ }^{1}$ National Center of Analysis and Testing for Nonferrous Metals and Electronic Materials, Guobiao (Beijing) Testing \& \\ Certification Co., Ltd., Beijing 101407, China \\ ${ }^{2}$ China United Testing \& Certification Co., Ltd., Beijing 101407, China \\ ${ }^{3}$ Beijing Spacecrafts, Beijing 100094, China \\ ${ }^{4}$ Youke Publishing Co., Ltd., Grinm Group Co., Ltd., Beijing 100088, China \\ ${ }^{5}$ Guangdong Provincial Academy of Building Research Group Co., Ltd., Guangzhou, 510500, China
}

Correspondence should be addressed to Xuelong Hao; xlhaogrinm@126.com

Received 4 August 2020; Revised 16 November 2020; Accepted 7 December 2020; Published 21 December 2020

Academic Editor: Alberto Álvarez-Gallegos

Copyright (c) 2020 Xuelong Hao et al. This is an open access article distributed under the Creative Commons Attribution License, which permits unrestricted use, distribution, and reproduction in any medium, provided the original work is properly cited.

\begin{abstract}
Expert systems (ES) are widely used for engineering and manufacturing applications nowadays. In order to solve the problems in material selection in the aviation field, an aircraft material expert system (AMES) was developed. This expert system is based on the knowledge of multiple experts and aviation data. A decision support system (DSS) was designed for selecting the materials used in aviation fields. The flows of material selection were designed, and the models of AMES were established. A data base system was also designed to implement AMES.
\end{abstract}

\section{Introduction}

Aviation engineering application fields are developing towards intelligence, digitalization, and integration [1]. It is complicated to select an appropriate material for aircraft design [2]. In order to meet the demands of the aviation development, expert systems (ES) have been used in aerospace and have solved a lot of problems successfully [3-5].

Expert systems were developed by the AI (artificial intelligence) community in the mid-1960s [6]. With the development of science and technology, ES was successfully used for engineering and manufacturing applications and dealing with complicated problems in aviation fields [7-14]. Liu et al. [15] studied the optimization of short-haul aircraft schedule recovery problems by using a hybrid multiobjective genetic algorithm. Li et al. obtained a semantic-based approach for collaborative aircraft tooling design [16]. Athanasopoulos [17] developed an ES for coating selection based on fuzzy and multicriterion decision-making. Grainer and Blunt [18] presented a thorough analysis of the properties and the applications of using a simpler material for the substrate; the engi- neers can diminish the cost of purchase. Mao-Jiun and Wang [19] designed an ES for tool steel material selection under fuzzy environment. Kim et al. [20] developed an expert system for fatigue life prediction under variable loadings.

However, all these expert systems were developed to solve problems without considering the whole capabilities of aircrafts. In this paper, an aircraft material expert system (AMES) on the capability and layout of aircraft was developed based on the knowledge of multiple experts and aviation data. A decision support system (DSS) was designed, and the flows were modeled by ES for aircraft material selection.

This paper is organized as follows: Sections 2-4 present the design of AMES and the model of selection flows of core functions. Sections 5 and 6 present the data base system of AMES and the data frame. An example of ES solution is given in Section 7. Section 8 contains brief conclusions.

\section{Design of AMES}

The frame of AMES was designed as shown in Figure 1. 


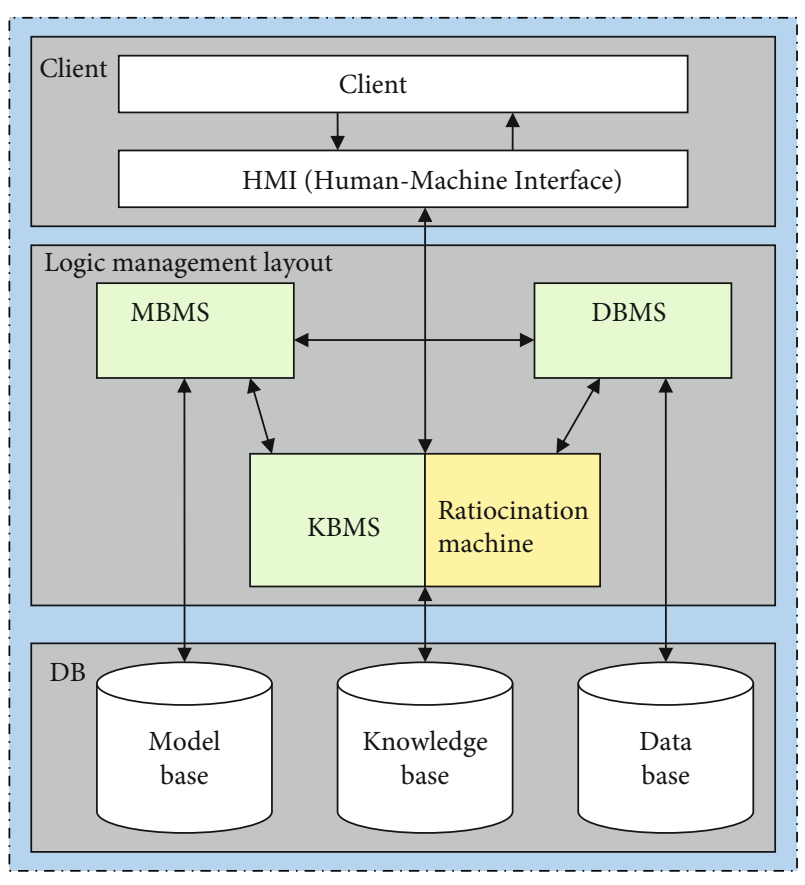

FIgURE 1: Frame of AMES.

The flow of AMES is as follows: clients visit the system via the HMI (human machine interface), and then the system transfers the request of clients to $\mathrm{DB}$ and returns the results to the clients.

The system contains three parts: client, logic management layout, and DB.

The core function logic of AMES is discussed in the second part. It contains the ratiocination and calculation of ES: ratiocination machine and the flow of material selection: MBMS (model base management system), DBMS (data base management system), and KBMS (knowledge base management system). The details will be given in Sections 3 and 4 .

The core business logic of AMES is designed in Part 3: DB. It contains MB (model base), KB (knowledge base), and $\mathrm{DB}$ (data base). MB contains the methods of material selection which are formed from the experience of the experts. $\mathrm{KB}$ contains the knowledge of aircrafts and materials and the experts' knowledge. DB contains the data which is used to assist clients to make decisions of material selection. The data base management system and the data frame are designed and given in Sections 5 and 6.

\section{Selection Methods of AMES}

The ratiocination and calculation methods are designed by ES.

Qualitative and quantitative properties are needed to be considered to select an appropriate material for aircraft use. So the DSS of AMES is based on fuzzy logic and multicriterion decision-making theories. As the decision is made by multiexpert and fuzzy multiattribution, a prototype of the multicriterion neural network (NN) system is applied to prototype system functionality approach.

The prototype is established and operated as follows:

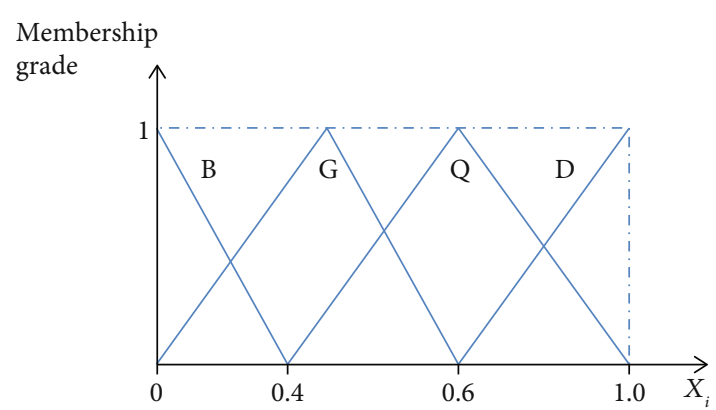

Figure 2: Membership functions for linguistic rating values.

The membership functions for linguistic ratings can be defined by the functions in Figure 2 [21].

It is assumed that the system has $r$ input variables $x_{i}(i$ $=1,2, \cdots, r)$ and $y_{j}(j=1,2, \cdots q)$.

The fuzzy membership function is defined as

$$
R_{t}=\frac{1}{n}\left(X_{i t 1} \oplus X_{i t 2} \oplus X_{i t 3} \cdots \oplus X_{i t 1}\right),
$$

where $i=1,2, \cdots m, t=1,2, \cdots k, R_{t}$ is the aggregate ratings of alternative I under criterion $t$, and $X_{i t n}$ are the assigned ratings of alternative I under criterion $t$ by decision-maker $n$. The symbol " $\oplus$ " is a proposed calculation method.

Similarly, if $G_{t}$ is the aggregated weighting for criterion $t$, and $k$ is the number of criteria. Then, their opinions can be aggregated by

$$
G_{t}=\frac{1}{n}\left(G_{i t 1} \oplus G_{i t 2} \oplus G_{i t 3} \cdots \oplus G_{i t 1}\right) .
$$

$U_{i}$ is defined as the approximated fuzzy number of the fuzzy suitability index. And $f(x)$ is defined as $M$ with the membership function. The symbol " $\oplus$ " is a proposed calculation

If the rule amount $X$ is given, the prototype of the system is established as

$$
U_{i}=\left(\frac{1}{k}\right) \otimes\left[\left(R_{t 1} \otimes G_{t 1}\right) \oplus\left(R_{t 2} \otimes G_{t 2}\right) \oplus \cdots \oplus\left(R_{t k} \otimes G_{t k}\right)\right] .
$$

If $x_{1} \leq x \leq x_{2}, f(x)=\left|\left(x-x_{1}\right)\left(x_{1}-x_{2}\right)\right|$; otherwise, $f(x)$ $=0$. Then, we can get the following result:

$$
M\left(U_{i}\right)=\frac{\left[M_{M}\left(U_{I}\right)+1-M_{G}\left(U_{i}\right)\right]}{2},
$$

where $M_{M}(U)$ and $M_{G}(U)$ are the maximizing set and the minimizing set, respectively, according to the input data. Equation (4) is the arithmetic of AMES.

\section{Core Function Models of AMES}

Equations (1)-(4) are the methods of material selection. It gives the flows of these methods. Four methods are designed 


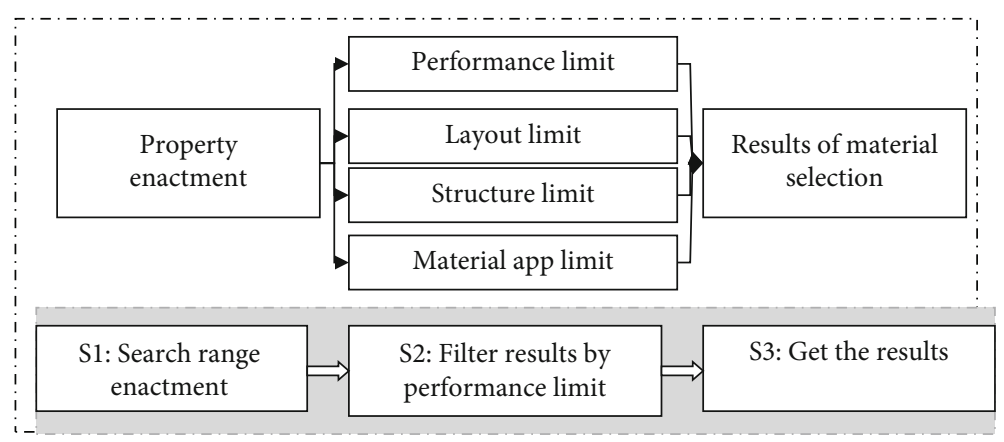

FIgURE 3: Methods of material selection: filter.

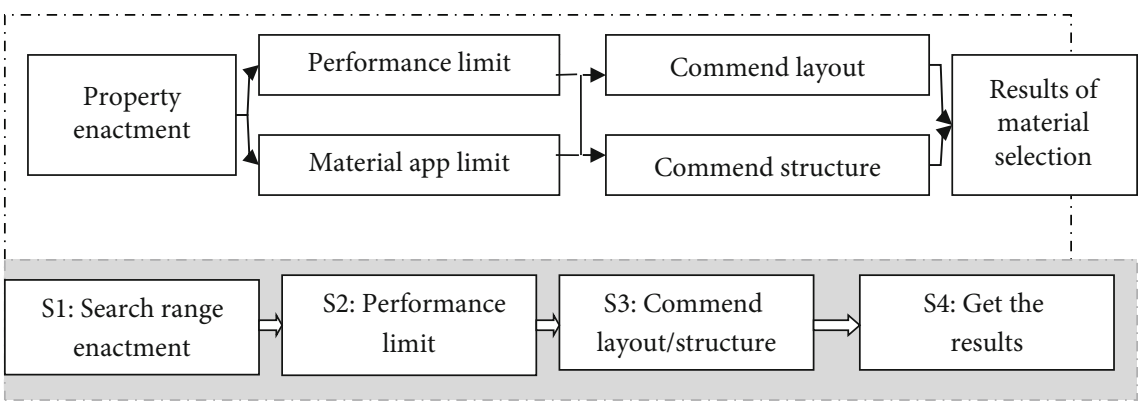

FIGURE 4: Methods of material selection: performance limit.

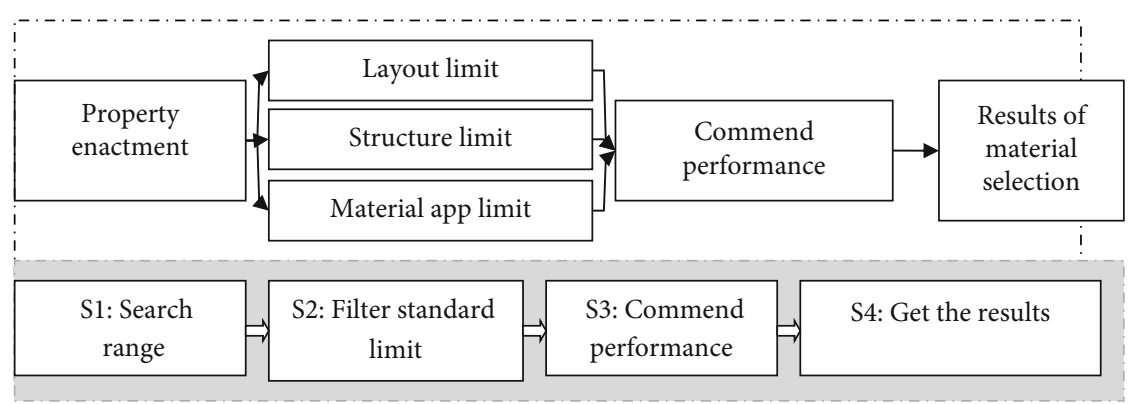

FIGURE 5: Methods of material selection: layout design.

to select materials for aircraft design: "filter," "performance limit", "layout design", and "experience." And the core function models are designed in Figures 2-5. The top of the figure gives the disposal flow of AMES. And the bottom gives the computer instruction of the flow.

The flow of "filter" is designed in Figure 3. Clients set the property conditions and the goals of material selection. The system filters the results by limiting the material performance. Then, the clients deal with the results returned by the system and choose the rights.

The flow of "performance limit" is described in Figure 4. After the properties were restricted, clients set the performance and the application of materials. Then, the system deals with the requests and commends the layout or structure of the aircraft. Clients could select the rights from the results returned by the system.

The flow of "layout design" is designed in Figure 5. This method commends the aircraft's performance through limit- ing the layout and structure of the aircraft. The method is often used by engineers to manufacture parts and so on.

The flow of "experience" is designed in Figure 6. This method depends on the experience of experts. It selects materials or parts based on the isometric spectrum. A lot of work is needed to ensure the validity of this method. But this method of material selection is the most useful way for aircraft designers.

\section{Actualization Technique of AMES}

After determining the frame and the core function, the actualization technique of AMES is designed.

As described in Figure 7, the frame of the DBMS (data base management system) is contrived by JCDF (Java Common Development Frame). It contains four lays: client layer, view layer, business layer, and resource layer. The differences of this frame from usual frames 


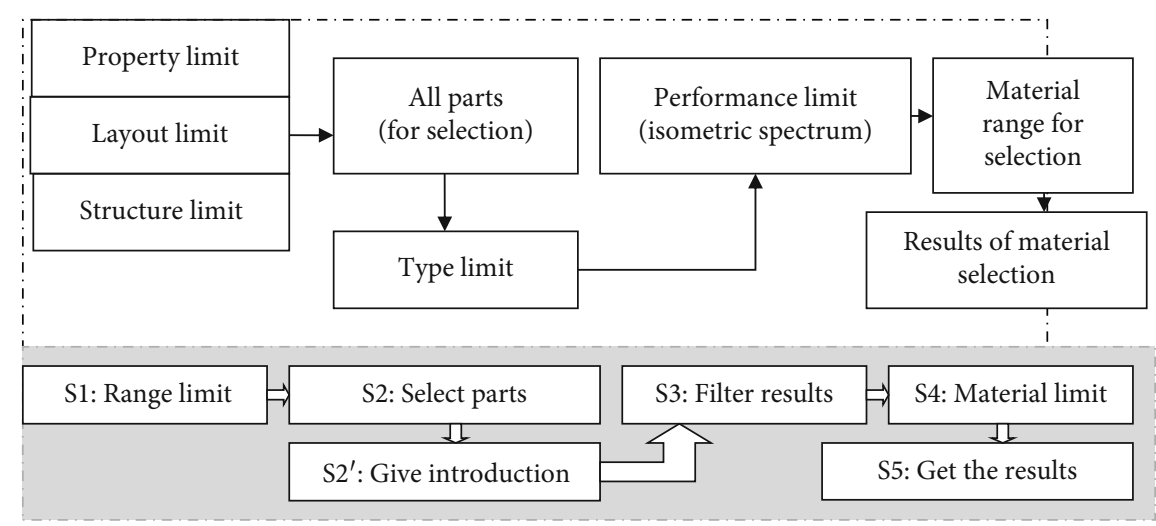

FiguRE 6: Methods of material selection: experience.

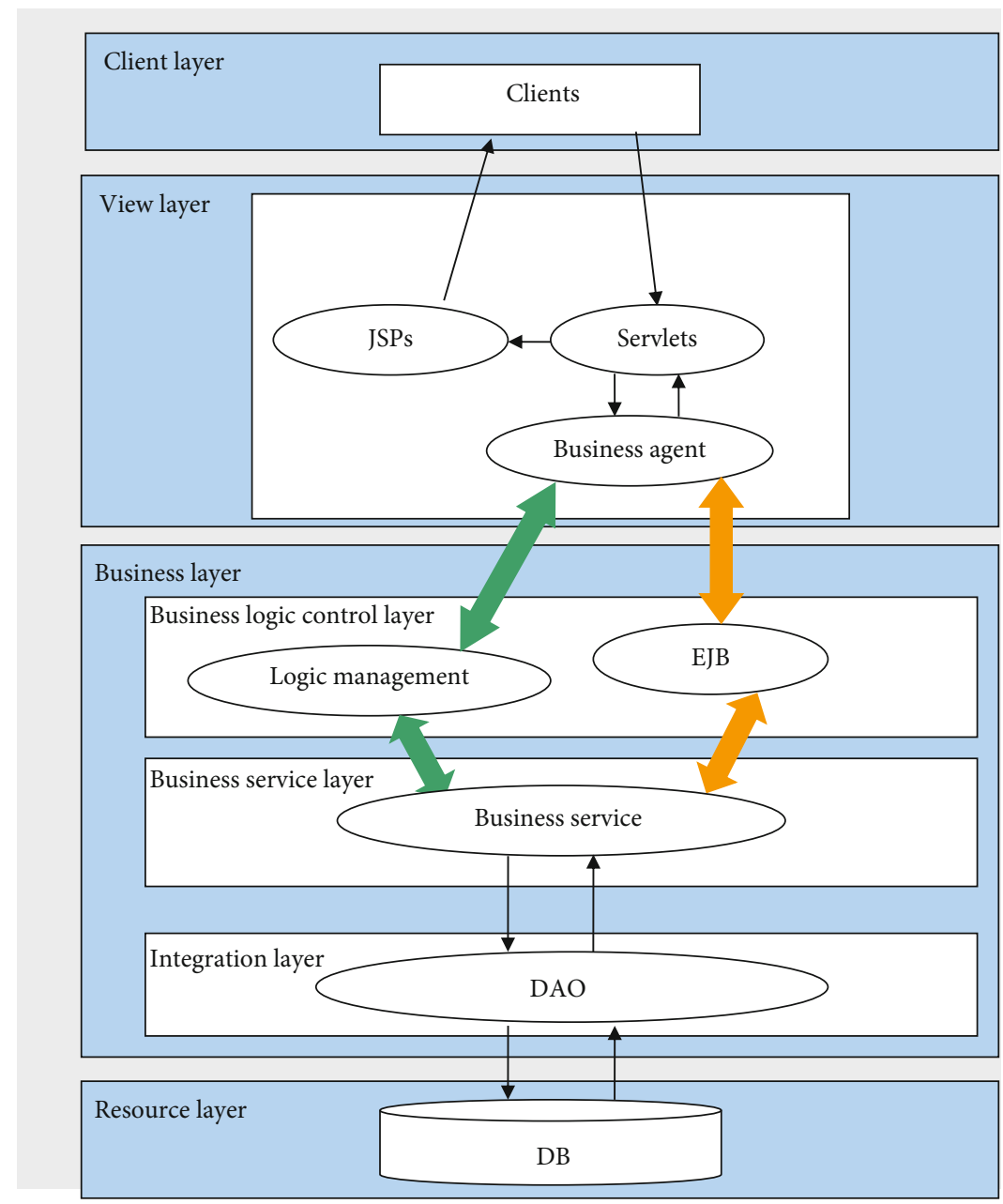

FIgURE 7: DBMS of AMES.

are as follows: the Servlets separate the view layer from the business layer, and the logic management is done by EJB. These sets promote the system to run fast and efficiently. JCDF can choose different flows to deal with different requests. It visits the data base via DAO and saves a lot of space.

\section{BL (Business Logic) of AMES}

In order to realize the transfer of the data successfully and make sure the system is easy to use, the design of the data base is important. The BL of AMES contains the model base, knowledge base, and data base. The model base and the knowledge 
TABLE 1: Frame of data base.

\begin{tabular}{|c|c|c|}
\hline \multirow{17}{*}{ AMES (BL) DB } & \multirow{4}{*}{ Aircraft information module } & $\begin{array}{c}\text { Aircraft property } \\
\text { Aircraft performance }\end{array}$ \\
\hline & & Aircraft layout \\
\hline & & Aircraft structure \\
\hline & & Aircraft material app \\
\hline & \multirow{5}{*}{ Component information module } & Component property \\
\hline & & Component performance \\
\hline & & Component layout \\
\hline & & Component structure \\
\hline & & Component material app \\
\hline & \multirow{4}{*}{ Part information module } & Part property \\
\hline & & Part performance \\
\hline & & Part structure \\
\hline & & Part material app \\
\hline & \multirow{4}{*}{ Material information module } & Material property \\
\hline & & Material component \\
\hline & & Material performance \\
\hline & & Material application \\
\hline
\end{tabular}

base contain expert experience and aircraft knowledge. But the data base should be arranged reasonably, or the system could run with a lot of problems. The data base of AMES contains aircraft information, component information, part information, and material information. These are outlined in Table 1. Every module has its own values, but they are related. The parameters of the whole aircraft and parts are based on the material.

\section{Example}

In this section, we use a new method based on equation (6) and give an example to illustrate the proposed method.

Firstly, let us consider the linguistic terms: disqualification (D), qualified (Q), good (G), and best (B). The fuzzy numbers corresponding to the terms are given in Table 2. The values present the limits of the selection.

$$
\begin{array}{r}
\text { D is equal to } \frac{1+1+0.6+0.6}{4}=0.8, \\
\text { Q is equal to } \frac{0.6+0.6+0.4+0.4}{4}=0.5 \text {, } \\
\text { G is equal to } \frac{0.4+0.4+0+0}{4}=0.2 \text {, } \\
\text { B is equal to } \frac{0+0.4+0+0}{4}=0.1 .
\end{array}
$$

We choose four $X_{i}$ variables $X_{1}$ (performance limit), $X_{2}$ (layout limit), $X_{3}$ (structure limit), and $X_{4}$ (material app limit) as given in Section 2, which are given in the method "filter." Then, we get the defuzzified values. Assume that the ratings of the program under four criteria decided by decision-makers are as shown in Table 3.
TABLE 2: Linguistic terms and corresponding fuzzy numbers.

\begin{tabular}{lc}
\hline Linguistic terms & Fuzzy numbers \\
\hline Disqualification (D) & $1,1,0.6,0.6$ \\
Qualified (Q) & $0.6,0.4,0.4,0$ \\
Good (G) & $0.4,0.4,0,0$ \\
Best (B) & $0,0.4,0,0$ \\
\hline
\end{tabular}

TABLE 3: Ratings of design plan of ES under the four criteria.

\begin{tabular}{lcccc}
\hline Plan & $X_{1}$ & $X_{2}$ & $X_{3}$ & $X_{4}$ \\
\hline I & Q & G & G & B \\
II & G & B & B & Q \\
III & B & B & G & G \\
IV & B & G & G & Q \\
\hline
\end{tabular}

TABLE 4: The importance weights of the four criteria.

\begin{tabular}{llllll}
\hline \multirow{2}{*}{ Criteria } & \multicolumn{5}{c}{ Decision } \\
& A & B & C & D & IW \\
\hline$X_{1}$ & Q & B & G & G & 0.25 \\
$X_{2}$ & G & Q & B & Q & 0.325 \\
$X_{3}$ & Q & G & B & B & 0.225 \\
$X_{4}$ & G & B & B & G & 0.15 \\
\hline
\end{tabular}

A committee of four decision-makers conducts this task and gives the decision also based on Table 2. The important weights of the four criteria are shown in Table 4. 
Based on the equations, the ranking values can be evaluated as follows:

$$
\begin{aligned}
M(\mathrm{I})= & 0.5 \times 0.25+0.2 \times 0.325+0.2 \\
& \times 0.225+0.1 \times 0.15=0.25, \\
M(\mathrm{II})= & 0.2 \times 0.2815+0.1 \times 0.34375+0.1 \\
& \times 0.25+0.5 \times 0.1875=0.18, \\
M(\mathrm{III})= & 0.1 \times 0.2815+0.1 \times 0.34375+0.2 \\
& \times 0.25+0.2 \times 0.1875=0.1325, \\
M(\mathrm{IV})= & 0.1 \times 0.2815+0.2 \times 0.34375+0.5 \\
& \times 0.25+0.5 \times 0.1875=0.21 .
\end{aligned}
$$

From the above calculations, the best selection is program III.

\section{Conclusions}

This paper developed an aircraft material expert system (AMES) to solve the problems of material selection in the aviation field. It provides a way of material selection by considering the whole performance of aircrafts by ES.

A selection method of fuzzy logic and multicriterion decision-making theories is designed by multiexpert and fuzzy multiattribution. And the prototype of the multicriterion neural network (NN) system is applied to the prototype system functionality approach. The computerized flows of selecting materials are also designed.

A DBMS is designed for realizing the core functions of AMES. A data base system is also designed for carrying out AMES.

Based on the knowledge of multiple experts and aviation data, the decision support system (DDS) could be used for selecting the materials used in aviation fields.

\section{Data Availability}

The data used to support the findings of this study are available from the corresponding author upon request.

\section{Conflicts of Interest}

The authors declare that they have no conflicts of interest.

\section{Authors' Contributions}

Xuelong Hao and Chen Wen contributed equally to this work.

\section{Acknowledgments}

(1) This study was financially supported by the National New Material Testing and Evaluation Platform construction project-nonferrous metal material industry (bidding no.: TC190H3ZW/2). (2) This study was financially supported by the National New Material Testing and Evaluation Platform main center project (bidding no.: TC170A5SU-1).

\section{References}

[1] Z. Y. Shen Jun, "Progress and layout for the database domain of aeronautical material," Aeronautical material transaction, vol. 23, p. 291, 2003.

[2] A. Jahan, M. Y. Ismail, S. M. Sapuan, and F. Mustapha, "Material screening and choosing methods - A review," Mater Des, vol. 31, no. 2, pp. 696-705, 2010.

[3] B. S. Adamczyk, A. L. Szejka, and O. Canciglieri Júnior, "Knowledge-based expert system to support the semantic interoperability in smart manufacturing," Computers in Industry, vol. 115, p. 103161, 2020.

[4] J. Liebowitz, "Expert systems: a short introduction," Engineering Fracture Mechanics, vol. 50, no. 5-6, pp. 601-607, 1995.

[5] M. D. Hassan, "An evaluation of input and output of expert systems for selection of material handling equipment," Journal of Manufacturing Technology Management, vol. 25, no. 7, pp. 1049-1067, 2014.

[6] S.-H. Liao, "Expert system methodologies and applications-a decade review from 1995 to 2004," Expert Systems with Applications, vol. 28, no. 1, pp. 93-103, 2005.

[7] H.-S. Shih, H.-J. Shyur, and E. S. Lee, "An extension of TOPSIS for group decision making," Mathematical and Computer Modelling, vol. 45, no. 7-8, pp. 801-813, 2007.

[8] V. Goel and J. Chen, "Application of expert network for material selection in engineering design," Computers in Industry, vol. 30, no. 2, pp. 87-101, 1996.

[9] A. Loganathan and I. Mani, "A fuzzy based hybrid multi criteria decision making methodology for phase change material selection in electronics cooling system," Ain Shams Engineering Journal, vol. 9, no. 4, pp. 2943-2950, 2018.

[10] A. Giorgetti, C. Cavallini, G. Arcidiacono, and P. Citti, "A mixed C-VIKOR fuzzy approach for material selection during design phase: a case study in valve seats for high performance engine," International Journal of Applied Engineering Research, vol. 12, no. 12, pp. 3117-3129, 2017.

[11] S.-K. Kim, M.-I. Roh, and K.-S. Kim, "Evaluation of feasibility index in the arrangement design of an offshore topside based on the automatic transformation of experts' knowledge and the fuzzy logic," Ocean Engineering, vol. 130, pp. 284-299, 2017.

[12] R. Nourian, S. M. Mousavi, and S. Raissi, "A fuzzy expert system for mitigation of risks and effective control of gas pressure reduction stations with a real application," Journal of Loss Prevention in the Process Industries, vol. 59, pp. 77-90, 2019.

[13] D. İçen and S. Günay, "Design and implementation of the fuzzy expert system in Monte Carlo methods for fuzzy linear regression," Applied Soft Computing, vol. 77, pp. 399-411, 2019.

[14] C. Urrea, G. Henríquez, and M. Jamett, "Development of an expert system to select materials for the main structure of a transfer crane designed for disabled people," Expert Systems with Applications, vol. 42, no. 1, pp. 691-697, 2015.

[15] T.-K. Liu, C.-H. Chen, and J.-H. Chou, "Optimization of shorthaul aircraft schedule recovery problems using a hybrid multiobjective genetic algorithm," Expert Systems with Applications, vol. 37, no. 3, pp. 2307-2315, 2010.

[16] Y. Li, R. Yan, and J. Jian, "A semantics-based approach for collaborative aircraft tooling design," Advanced Engineering Informatics, vol. 24, no. 2, pp. 149-158, 2010. 
[17] G. Athanasopoulos, C. R. Riba, C. A. G. Athanasopoulos, C. R. Riba, and C. Athanasopoulou, "A decision support system for coating selection based on fuzzy logic and multi-criteria decision making," Expert Systems with Applications, vol. 36, no. 8, pp. 10848-10853, 2009.

[18] S. B. Grainer, "Engineering coatings," Design and applications. Cambridge: Abington Publishing, pp. 445-446, 1998.

[19] M.-J. J. Wang, T.-C. C. M.-J. J. Wang, and T.-C. Chang, "Tool steel materials selection under fuzzy environment," Fuzzy Sets and Systems, vol. 72, no. 3, pp. 263-270, 1995.

[20] Y.-H. Kim, J.-H. Song, and J.-H. Park, “An expert system for fatigue life prediction under variable loading," Expert Systems with Applications, vol. 36, no. 3, pp. 4996-5008, 2009.

[21] S.-M. Chen, "A new method for tool steel materials selection under fuzzy environment," Fuzzy Sets and Systems, vol. 92, no. 3, pp. 265-274, 1997. 